\title{
LA EXCEPCIÓN RATIFICA LA REGLA. CONSIDERACIONES SOBRE LA COERCIBILIDAD Y LA GENERALIDAD DE LA NORMA
}

\author{
Carlos Manuel Rosales \\ Maestro y Doctor en Derecho \\ por la Universidad de Chile \\ Investigador Invitado por el Instituto Nacional \\ de Ciencias Penales (INACIPE), México \\ Investigador del Centro de Investigación \\ y Docencia Económicas (CIDE), México \\ cmr268@yahoo.com
}

\section{INTRODUCCIÓN}

Una ambulancia es manejada con exceso de velocidad, se estaciona en lugar prohibido para recoger a una persona lesionada que sufrió un accidente y en su viaje al hospital este vehículo es conducido en contrasentido de la vialidad, incumpliendo diversas condiciones del reglamento de tránsito. Sin duda debe haber sanciones a estas infracciones, pero puede suceder (como en el caso expuesto) que se exceptúe de sanción al sujeto.

La ley tiene fines específicos, como otorgar derechos, libertades u obligaciones a las personas, y con esto poder generar seguridad. La forma en cómo debe respetarse y ejecutarse la norma será la base para que se protejan los objetivos de una sociedad. En el caso mostrado se cuenta con una legislación especializada para el manejo de vehículos, lo que genera un patrón de comportamiento para los conductores, y en caso de conculcar esas disposiciones se debe castigar al infractor. Sin embargo, entendiendo la naturaleza del acto, ¿se debería anular la imposición de una sanción por haber salvado la vida de una persona o, como cualquier conductor, el operador de la ambulancia debe ser sancionado por incumplir la norma jurídica? ${ }^{1}$

${ }^{1}$ A. Gordillo, Introducción al Derecho, cap. III, Buenos Aires, Fundación de Derecho Administrativo, 2000, p. 3. 
El Derecho, como un sistema de normas generales, sirve para la regulación de conductas y la protección de los derechos y libertades de las personas. Las leyes tienen ciertas características. Un par de ellas son: el origen y ciertos principios que los instauran como agentes regentes ${ }^{2}$.

De esta forma, las normas tienen eficacia y validez no sólo por su origen democrático (legitimidad) ${ }^{3}$, sino porque varios principios (heteronomía, inalienabilidad, imparcialidad, generalidad, coercibilidad e impersonalidad) las apuntalan como la base del Derecho ${ }^{4}$.

Sin embargo, los principios que cimientan las normas no son absolutos, sino que se relativizan según sea el caso, creándose áreas de exclusión, por lo que se originan excepciones a la generalidad de la norma y al cumplimiento absoluto de la misma.

El presente trabajo expone diversos casos en los que la norma jurídica podría ser ejecutada sin ninguna sanción ${ }^{5}$, por lo que hay una exclusión en la aplicación del Derecho (si el caso lo amerita). Pongamos otro ejemplo: se está incendiando la casa del vecino y para proteger la propiedad personal se debe ingresar sin autorización a la propiedad vecina para extinguir el fuego. Es evidente la invasión a una propiedad ajena sin aviso, ejecutando conductas prohibitivas que permiten la privacidad y seguridad del domicilio, empero la racionalidad nos aproxima a un estadio que nos dirige a pensar y valorar qué es más importante, la inviolabilidad de su domicilio o la protección de su patrimonio. Y aquí viene el tema que se explora, bajo qué supuestos una norma podría no ser instrumentalizada para castigar una violación a la ley o dejar sin efecto la sanción propuesta por la autoridad reguladora ${ }^{6}$. Esto crea un espacio para comprender que las normas no siempre son generales, sino que hay un espacio y un momento en que la situación y el criterio del sentido común hacen tolerar ciertos hechos por un beneficio colectivo.

Por tanto, comenzaremos este artículo exponiendo de manera breve qué es la norma, cuál es su función y la característica de la generalidad,

${ }^{2}$ H. L. A. Hart, El concepto del Derecho, Buenos Aires, Abeledo-Perrot, 1989, pp. 4 y 64.

3 H. L. A. Hart, «The Ascription of Responsibility and Rights», Proceedings of the Aristotelian Society, New Series, vol. 49 (1949), pp. 171-194.

${ }^{4}$ Estos principios tienen un valor intrínseco y justifican su instrumentación para generar el fundamento de su validez. Vid. N. BoвBio, Teoría general del Derecho, Madrid, Debate, 1991, pp. 141-150.

5 B. García Camino, «La excepción en el Derecho», Revista Foro, vol. 16, núm. 1 (2013), pp. 84 y ss.

6 J. Rawls, Political Liberalism, New York, Columbia University Press, 2005, pp. 203-230. 
con el objetivo de visualizar la fuerza coercitiva y deontológica que contienen las normas para garantizar seguridad, derechos, libertades, etc. ${ }^{7}, \mathrm{y}$ que la violación de las mismas atenta a lo que se desea como sociedad y, por tanto, todo incumplimiento debe ser castigado según sea dañado el bien tutelado ${ }^{8}$.

Posteriormente se analizarán una serie de casos en los que se observa el incumplimiento de la norma en pos de tutelar un bien jurídico, como podría ser la vida, la salud, la seguridad o alguna libertad, para que se contraste la norma que prohíbe ciertos actos y pueda no ejecutarse la sanción a quien haya violentado la ley de manera justificada ${ }^{9}$, vigilando el fin teleológico del Estado, la protección de los bienes primordiales y los derechos fundamentales.

Con ambos lados de la balanza se presentará, por un lado, el deber del cumplimiento de la norma sin excepciones y, por otro, lo que el sentido común propone: cuidar un bien jurídicamente tutelado (que lógicamente es superior a la ejecución estricta de un reglamento o de alguna ley).

El objeto del presente trabajo es encontrar un espacio para la filosofía y la justicia en el que la norma aplicada y entendida de manera estricta podría producir injusticias y donde hay casos en que la inaplicación de una sanción es la mejor forma de finalizar el incumplimiento de la misma, dependiendo del contexto y las circunstancias.

\section{LA NORMA JURÍDICA}

El estudio de la norma tiene diferentes aristas, desde su origen, su elaboración, su validez, su objetivo, su interpretación y su reformulación ${ }^{10}$. Por su origen éstas pueden emanar de dos fuentes: las heterónomas, que provienen de terceros y que se hacen de observación general por ser elaboradas por una persona o institución con un poder delegado (por ejemplo, la Iglesia, una asamblea, un parlamento), y las autónomas, que son las que construye el individuo en uso de su criterio e interés personal ${ }^{11}$.

7 Vid. J. C. BAYÓN, «¿Por qué es derrotable el razonamiento jurídico?», Revista Doxa, núm. 24 (2001), pp. 35-62.

8 J. CÁRDENAS, Introducción al estudio del Derecho, México, UNAM, 2016, p. 102.

9 L. GReCo, «Las reglas detrás de la excepción», Revista para el Análisis del Derecho, núm. 2 (2007), p. 159.

${ }^{10}$ H. L. A. HarT, El concepto del Derecho, op. cit., p. 114.

${ }^{11}$ Ibid., pp. 26 y 104. 
Las normas deben contar con un numen que les de vigencia, es decir, deben estar revestidas de legitimidad ${ }^{12}$. Por lo que la norma se convierte en el instrumento jurídico para tutelar, proteger o realizar un fin específico (propiedad, nacionalidad, indemnización, etc. $)^{13}$.

En cuanto a la interpretación de la norma, ésta dependerá del contexto en que se haga, pues los individuos y la autoridad la realizaran conforme sea el caso, pudiendo hacerse de manera estricta, armónica, legal, objetiva o finalista, entre otras ${ }^{14}$. En este estadio, mucho dependerá de los intereses de los partes y de lo que se pretende obtener con dicha interpretación.

Por lo que respecta a la reformulación de la norma, ésta se realiza a partir de su efectividad o su empate con la realidad social ${ }^{15}$, en una forma de utilitarismo social, para que se revalide su existencia o vigencia, o de plano su abrogación, según sea el caso ${ }^{16}$.

Las normas jurídicas tienen como fuente una autoridad con poder (el mismo que se les ha delegado para crearlas). Las leyes, para existir, deberán ser producidas con ciertos requisitos de forma (un proceso legislativo y de compatibilidad con el sistema jurídico vigente) ${ }^{17}$. Ahora bien, también pueden producirse desde el poder ejecutivo (en forma de decreto en el que se revisará que su contenido se ajuste al Derecho positivo). Por último, también están las normas provenientes desde el poder judicial (legislación negativa), en el que señalará el significado de la norma, cómo debe ejecutarse y su efectividad en el andamiaje normativo ${ }^{18}$.

De esta forma, la norma se convierte en el instrumento con el cual se concretan los objetivos de una comunidad, se protejen determinados bienes, derechos y libertades, se tutelan valores y principios, y se garantiza la seguridad jurídica. En el que lo ideal será que la norma sea el reflejo de la sociedad ${ }^{19}$. Así, la ley se vuelva la materialización de la voluntad del soberano.

12 J. Rawls, Liberalismo político, México, FCE, 2011, pp. 40 y 56.

13 L. López Guerra, Algunas consideraciones sobre la devaluación de la ley, Managua, INEJ, 2011, pp. 107 y ss.

${ }_{14}$ M. VILLORO Toranzo, «La norma jurídica y sus caracteres», Revista de la Facultad de Derecho, núm. 111 (1978), pp. 857 y ss.

15 J. Rawls, Liberalismo político, op. cit., p. 131.

${ }^{16}$ H. L. A. Hart, El concepto del Derecho, op. cit., pp. 8 y 15.

17 Ibid., p. 41.

18 Vid. V. Tinoca, «La motivación como sustento de la sentencia objetiva y materialmente justa», Revista del Poder Judicial, año 6, núm. 9 (2012).

19 R. RuIZ, «La distinción entre reglas y principios», Revista Derecho y Realidad, núm. 20 (2012), pp. 145 y ss. 


\section{CARACTERÍSTICAS DE LA NORMA JURÍDICA}

Las normas jurídicas están revestidas de ciertos principios para que sean válidas ${ }^{20}$. Éstos, como ya se expuso, son: heteronomía, inalienabilidad, imparcialidad, generalidad, coercibilidad e impersonalidad. Los mismos que dan fuerza y coherencia a un sistema normativo.

El profesor Ronald Dworkin define el término «principio» como una pauta que ha de observarse, porque es una exigencia de la justicia, de la equidad o de otro aspecto de la moral. Por lo mismo, «los principios inclinan la decisión en una dirección, aunque no de manera concluyente, y sobreviven intactos aun cuando no prevalezcan» ${ }^{21}$. Es decir, para Dworkin «los principios son la base que construyen los sistemas jurídicos, irradiándose a todo el sistema jurídico» ${ }^{22}$.

Los principios son abstractos, de contenido impreciso e incierto, y han llegado para quedarse ${ }^{23}$, porque constituyen «los presupuestos que hacen posible la democracia, además de que se establecen como un vínculo preventivo que se autoimpone la comunidad para autoprotegerse y no perder el rumbo» ${ }^{24}$.

Según Atienza, los principios tienen las siguientes funciones:

«1. Función creativa: antes de promulgar la norma jurídica el legislador debe conocer los principios para inspirarse en ellos y poder positivizarlos.

2. Función interpretativa: implica que al interpretar la norma, el operador debe inspirarse en los principios para garantizar una cabal interpretación.

${ }^{20}$ H. L. A. HART, El concepto del Derecho, op. cit., p. 126.

${ }^{21}$ Ronald DwORKIN estima que los principios jurídicos no son patrones extrajurídicos y son vinculantes para el juez. R. Dworkin, Los derechos en serio, Barcelona, Ariel, 1995, pp. 19-22.

22 Ibid., pp. 77 y 78. Esta concepción la tomó basándose en que a partir de los principios se crean las normas. Básicamente, la distinción que hace DwORKIN entre reglas y principios es que las normas jurídicas prescriben una conducta con su consecuencia jurídica, mientras que los principios carecen de dicha consecuencia en razón de que se trata de planteamientos que ayudan a tomar posición ente los casos concretos. Son orientadores, estándares de conducta. Por tanto, los principios son superiores a la norma.

${ }_{23}$ B. BIX, Jurisprudence, Durham, Carolina Academic Press, 2004, p. 88.

${ }^{24}$ P. Salazar, «Justicia constitucional y democracia: el problema de la última palabra», en R. VÁzquez (coord.), Corte, jueces y política, México, Fontamara, 2007, p. 42. 
3. Función integrativa: significa que quien va a colmar un vacío legal debe inspirarse en los principios para que el Derecho se convierta en un sistema hermético.

Estas funciones no actúan independientemente, sino que la aplicación del Derecho opera una u otra» ${ }^{25}$.

La norma, para tener validez, eficiencia y utilidad, debe estar revestida de las características antes señaladas. Su efectividad se refleja en la ejecución imparcial, profesional y objetiva de las mismas, y su legitimidad se adquiere por medio del reconocimiento social al trabajo del poder público.

El objetivo de las normas es vivir en armonía, convivencia, seguridad y protección, por lo que la sociedad debe sentirse contenida y reflejada en lo norma y sentir una identidad, y las sentencias jurisdiccionales deben contener en cada resolución la coincidencia de lo que se desea como Estado.

Sin embargo, estos principios que validan y legitiman a las normas pueden tener alguna excepción. A priori, se respondería que la falta de aplicación de algunos de éstos crearía un acto nefasto, parcial y corrupto. Pero en nuestro caso específico se podría dejar de utilizar la generalidad de la norma para crear espacios de actuación que salvaguarden los valores de una sociedad.

La norma jurídica es general e incoercible, no hay excepción para su acatamiento, todos deben obedecerla, es obligatoria; es lo que se advierte cuando se analiza y estudian sus características. Pero no se menciona en la doctrina si existen casos de excepción en los que la ley o la sanción podría dejar de aplicarse.

La generalidad de la norma es entendida con base en que la ley está elaborada para que todos los individuos se sometan a la misma ${ }^{26}$. No se considera o prevé en la doctrina jurídica un tema de excepcionalidad o de no aplicación de la sanción por incumplir la normatividad, pues fragmentaría el objetivo de los principios que la sostienen ${ }^{27}$. Esta definitividad es una determinación ciega y literal que no comprende los posibles estadios de incumplimiento a la ley sin que sean sancionados ${ }^{28}$.

25 Vid. M. Atienza, Las razones del Derecho, México, UNAM, 2005.

${ }^{26}$ P. Sorokin, «Características de las normas jurídicas», Revista Chilena de Derecho, vol. 9, núm. 2 (1982), pp. 471 y ss.

27 E. García Máynez, Introducción al Derecho, México, Porrúa, 2002, pp. 18-24.

${ }^{28}$ J. C. BAYÓN, «Sobre la racionalidad de dictar y seguir reglas», Revista Doxa, núm. 19 (1996), pp. 143 y ss. 
Pongamos otro ejemplo: alguien enferma repentinamente en su casa y un menor de edad que convive con esa persona nota la gravedad en que se encuentra la persona, pero ese menor no es médico y aun así interviene a la persona con los debidos cuidados que le indican por teléfono. ¿Se justificaría iniciar un proceso administrativo o penal al que realizó actos de la profesión médica o se debería entender la naturaleza del caso urgente en donde la vida de alguien dependía de esa operación y, por tanto, no se debe reprender a esa persona?

La generalidad de la norma nos expresa claramente cómo deben ser las conductas de las personas en sociedad, pero si la necesidad es mayor y la norma es conculcada por la urgencia del caso, el sentido común nos advierte de la conservación de un bien primario.

Pongamos otro ejemplo: un policía es requerido porque está cometiéndose un delito de lesiones en un domicilio, ¿puede entrar al domicilio sin una orden judicial y que tampoco se cometa un abuso de autoridad? Una lógica autojustificativa de lo que parece lo justo llevaría a no sancionar, porque la autoridad realizó esa acción como parte de su trabajo y para la protección de la seguridad y la vida de una persona.

Podemos localizar diversas conductas que no se castigarían si se demuestra que se trataba de proteger o tutelar un bien jurídico y que la urgencia del caso excepciona de sanción ${ }^{29}$. Pero entonces se tendrían que considerar dos criterios para saber si se debe castigar aquella conculcación a la norma: uno de índole subjetivo (de lo justo), racionalizando una respuesta contenida de sentido común, y otro, por medio del establecimiento de un razonamiento judicial que haga inválida la infracción con la debida demostración del caso $^{30}$, dejando la carga de la prueba al sujeto, que recurrirá la sanción en un juicio en el que acompañará para su descargo las pruebas correspondientes, pretendiendo ser absuelto de los cargos que se le formulen.

De esta idea se desprende la naturaleza de este artículo. ¿Debe haber excepciones a la norma legal? Veamos un caso más: una zona señalada para «no nadar» en una playa. Una persona se está ahogando y otra se introduce para salvar la vida del otro. ¿Deberían ser ambos sancionados por incumplir con la señalización expresa de «no nadar» en ese lugar?

En general, podemos observar que puede haber tantas excepciones como motivos (inminentes y reales) para que no se ejecute la sanción

\footnotetext{
${ }^{29}$ H. L. A. HART, El concepto del Derecho, op. cit., p. 5.

30 J. RAWLS, Liberalismo político, op. cit., p. 173.
} 
correspondiente. ${ }^{31}$ Lo que produce tres criterios para analizar si se debe castigar ese incumplimiento de la normatividad ${ }^{32}$ :

a) Aplicación estricta. Sólo se observa el cumplimiento de la norma/ sanción y, por tanto, no hay ninguna consideración para que no sea atenuado o excluido de responsabilidad el infractor ${ }^{33}$.

b) Racionalidad (sentido común-justo-sin judicialización). En estos casos, la autoridad no jurisdiccional utiliza su sentido común y discreción para considerar los motivos y circunstancias del caso específico ${ }^{34}$. Con esto decide no iniciar un proceso contra la persona que vulneró la ley por una causa justa.

c) Razonabilidad (invalidación de la sanción-justicia-jurisdicción)Sistema probatorio ${ }^{35}$. Existe un tercer escenario, una autoridad jurisdiccional es la que reflexiona sobre si el infractor a la norma no podía ejercer otro tipo de conducta. Aquí la parte acusadora tendría que exponer el sentido de la norma, la conducta del individuo y la sanción que solicita contra el sujeto ${ }^{36}$. El juez en un sistema de descargos permitiría que la parte indiciada rinda sus pruebas que hagan convalidar sus dichos de no sancionabilidad por las circunstancias específicas del caso $^{37}$.

En palabras de Hart: «La nulidad puede no ser un mal para la persona que no ha satisfecho alguna condición exigida para la validez jurídica» ${ }^{38}$. Por lo que la determinación de no sancionar se tendría que justificar por ${ }^{39}$ :

a) Urgencia del caso.

b) Protección de un bien jurídico tutelado (vida, salud, libertad, etc).

c) Irreparabilidad del bien o del daño.

Por tanto, se puede establecer un espacio/tiempo para la inaplicación de sanciones y poder crear un precedente judicial para este tipo de

${ }^{31}$ H. L. A. Hart, El concepto del Derecho, op. cit., p. 127.

32 Vid. ibid., en concreto el cap. VII sobre la textura abierta.

33 A. SQuella, «Justificar decisiones jurídicas y justificar decisiones judiciales», Revista de Derecho, vol. 19, núm. 1 (2006), pp. 277 y ss.

${ }^{34}$ J. RaWLs, Liberalismo político, op. cit., pp. 173 у 194.

35 Ibid., p. 73.

${ }^{36}$ E. FigueroA, «Jueces y argumentación», Revista del Poder Judicial, año 6, núm. 9, (2012), p. 119.

${ }^{37}$ J. Rawls, Liberalismo político, op. cit., pp. 219 y ss.

38 H. L. A. HarT, El concepto del Derecho, op. cit., pp. 43 y 176.

39 Ibid., pp. 42 y ss. 
$\operatorname{casos}^{40}$ en los que la eficacia de la norma sea más importante que la validez de la misma:

«La idea del razonamiento y del juicio se aplica a nuestras aseveraciones morales y políticas; en lugar de la simple manifestación de nuestro estado psicológico, debemos ser capaces de emitir juicios y de colegir inferencias fundamentados en criterios y evidencias mutuamente reconocidos, y de esta manera, no de otra — por ejemplo, no por mera retórica ni por la persuasión—, podemos llegar a un acuerdo mediante el ejercicio libre de nuestros poderes de juicio» ${ }^{41}$.

Muchas personas, cuando ven normas que contienen excepciones, tienden a darles un alcance de regla general, siendo que la regla es exactamente la contrario, puesto que de otra manera lo excepcional se vuelve general.

Pensemos en el caso de los derechos fundamentales. Si usted encuentra una norma que consagra una excepción a la misma debe interpretarla restrictivamente, no en forma amplia, pues eso conllevaría negar el Derecho. Y no me refiero al in dubio pro libertate (entre dos interpretaciones de una norma debe preferirse aquella que supone mayor beneficio), sino a la forma de interpretar una excepción ${ }^{42}$. Veamos cómo lo formula la Corte Constitucional colombiana:

«En este orden de ideas, como lo ha sostenido reiteradamente esta Corporación, las normas que introducen excepciones a los derechos fundamentales son de interpretación restrictiva, pues la propia Constitución política les reconoce un orden preferente al darles primacía sobre el resto de disposiciones que conforman el ordenamiento jurídico (arts. 5. ${ }^{\circ}$ y $93 \mathrm{CP}$ ), a la vez que su protección, vigencia y salvaguarda constituye un fin esencial del Estado» ${ }^{43}$.

\section{CONSIDERACIONES ESPECIALES}

En el entendido de que toda norma perfecta contiene una sanción para que ésta sea respetada, en los casos expuestos el sentido común nos orienta a no sancionar esas infracciones a la ley. ¿En qué momento es más impor-

\footnotetext{
${ }^{40}$ Ibid., pp. 193 y ss.

${ }^{41}$ J. RaWls, Liberalismo político, op. cit., p. 119.

42 Sentencia C-010/00.

43 Sentencia C-095/00.
} 
tante el deber moral que el deber jurídico? En nuestros casos, el no castigar una conducta contraria a la ley es un ejercicio de lógica deductiva que tiene que ver con el análisis del caso y las circunstancias para la desobediencia de la norma ${ }^{44}$.

El tema relevante es el acto de proceder contra la norma, entendiendo que la norma permite establecer una apropiada convivencia y cumplir con los objetivos de la sociedad. Pero se debe extralimitar esa conceptualización cuando hay que salvaguardar un bien jurídico, aun en contra de la normatividad. Aquí se tiene una razón pública que guía a un ciudadano que en un ejercicio racional responde a la protección de los bienes primarios y que en un acto razonable no será sujeto de sanciones ${ }^{45}$.

¿Cómo se puede justificar la inaplicabilidad de la sanción? En este contexto se está sujeto a la comprensión del caso específico y que no existía exigibilidad de otra conducta por la premura del caso. En el deber o en la reacción no hay deliberación para hacer lo que impone la norma (esto se realiza en un instante, no es un acto premeditado). La justificación es intrínseca por el bien que se tutela. Entonces, la prelación de un bien tutelado está sobre la rigidez de la norma, lo que implica la teleología del Estado sobre la deontología de la norma.

Otro punto a considerar es revisar y comprobar por parte de la autoridad si se cumplieron los protocolos de actuación (si los hay) cuando el infractor a la norma sea un agente público, pues es su obligación y es el cabal desarrollo de sus funciones conforme lo marca la norma, el reglamento, las circulares y los protocolos bajo los que se rigen.

Este sistema de excepciones reformula el sentido de lo justo sobre la aplicación estricta y literal del marco normativo ${ }^{46}$. En los casos presentados se originó un espacio para que no sea sancionado el infractor existiendo causas justificadas.

Una de las formas en que podría darse este sistema de no sanción es por medio de la creación de un criterio jurisdiccional de excepción de aplicación de la sanción de la norma ante determinada emergencia y la obligada protección de un bien tutelado (vida, seguridad, paz, etc.). En el entendido de que no es un boleto a la impunidad, sino que se deben comprobar los motivos de esa conducta.

${ }_{44}$ M. C. Redondo, «La justificación de las decisiones judiciales», Revista Isegoria, núm. 21 (1999), pp. 149 y ss.

45 J. RAWLS, Liberalismo político, op. cit., pp. 205 y 207.

46 Vid. W. VÁzQuez, Excepción y necesidad. La posibilidad general de una teoría de la emergencia, Chile, SELA, 2010. 
Pero ¿qué pasaría en caso de un accidente donde se genere alguna responsabilidad de una autoridad o un civil? ¿Cómo sancionar en estos casos? Existe atenuante. Por ejemplo, un policía atropella a un peatón en una persecución vehicular. Se debe reevaluar su sanción y pena por ejercer su trabajo y ser parte del riesgo profesional.

\section{BIBLIOGRAFIA}

Atienza, M., Las razones del Derecho, México, UNAM, 2005.

BAYÓN, J. C., «¿Por qué es derrotable el razonamiento jurídico?», Revista Doxa, núm. 24 (2001), pp. 35-62.

— «Sobre la racionalidad de dictar y seguir reglas», Revista Doxa, núm. 19 (1996), pp. 143-162.

Bix, B., Jurisprudence, Durham, Carolina Academic Press, 2004.

Boвbio, N., Teoría general del Derecho, Madrid, Debate, 1991.

CÁrdenas, J., Introducción al estudio del Derecho, México, UNAM, 2016.

Dworkin, R., Los derechos en serio, Barcelona, Ariel, 1995.

FigueroA, E., «Jueces y argumentación», Revista del Poder Judicial, año 6, núm. 9 (2012), pp. 119-141.

García Camino, B., «La excepción en el Derecho», Revista Foro, vol. 16, núm. 1 (2013), pp. 83-109.

García Máynez, E., Introducción al Derecho, México, Porrúa, 2002.

Gordillo, A., Introducción al Derecho, Buenos Aires, Fundación de Derecho Administrativo, 2000.

GRECO, L., «Las reglas detrás de la excepción», Indret. Revista para el Análisis del Derecho, núm. 2 (2007).

Hart, H. L. A., «The Ascription of Responsibility and Rights», Proceedings of the Aristotelian Society, New Series, vol. 49 (1949), pp. 171-194.

- El concepto del Derecho, Buenos Aires, Abeledo-Perrot, 1989.

LÓPEz GUERRA, L., Algunas consideraciones sobre la devaluación de la ley, Managua, INEJ, 2011.

Rawls, J., Political Liberalism, New York, Columbia University Press, 2005.

- Liberalismo político, México, Fondo de Cultura Económica, 2011.

Redondo, M. ${ }^{a}$ C., «La justificación de las decisiones judiciales», Revista Isegoria, núm. 21 (1999), pp. 149-163.

Ruiz, R., «La distinción entre reglas y principios», Revista Derecho y Realidad, núm. 20 (2012).

SALAZAR, P., «Justicia constitucional y democracia: el problema de la última palabra», en R. VÁzQuez (coord.), Corte, jueces y política, México, Fontamara, 2007. 
Sorokin, P., «Características de las normas jurídicas», Revista chilena de Derecho, vol. 9., núm. 2 (1982), pp. 471-487.

Squella, A., «Justificar decisiones jurídicas y justificar decisiones judiciales», Revista de Derecho, vol. 19, núm. 1 (2006), pp. 277-292.

Vázquez, W., Excepción y necesidad. La posibilidad general de una teoría de la emergencia, Chile, SELA, 2010.

Villoro Toranzo, M., «La norma jurídica y sus caracteres», Revista de la Facultad de Derecho, núm. 111 (1978), pp. 857-874.

TinocA, V., «La motivación como sustento de la sentencia objetiva y materialmente justa», Revista del Poder Judicial, año 6, núm. 9 (2012). 